\title{
AMBIENTE REGULATIVO, RESPOSTAS ESTRATÉGICAS E QUALIDADE DE ENSINO SUPERIOR EM ORGANIZAÇÕES DE ENSINO SUPERIOR (IES) DO ESTADO DO PARANÁ
}

\author{
Legal environment, strategy and education \\ quality in higher education organizations
}

Envio 30.10.08 / Aceite 01.12.08

\author{
João Marcelo Crubellate ${ }^{1}$ \\ Ariston Azevedo Mendes ${ }^{2}$ \\ Ronei da Silva Leonel Junior ${ }^{3}$
}

\begin{abstract}
Resumo
O principal objetivo deste estudo foi investigar o significado de qualidade de ensino superior a partir das respostas estratégicas de Organizações de Ensino Superior (IES) do Estado do Paraná aos critérios estabelecidos pelo MEC no período de 2001 a 2003. O método que caracteriza o estudo é a pesquisa do tipo levantamento (survey). Foram utilizados dados secundários (legislação brasileira de ensino e informações disponibilizadas nos sites oficiais do MEC e do INEP) e, principalmente, dados primários, obtidos por meio de questionário estruturado enviado a 130 IES privadas do Estado do Paraná, no ano de 2004. Por meio de procedimentos estatísticos multivariados foi possível classificar 35 IES cujos dirigentes principais responderam ao questionário, enviando-o aos pesquisadores, de acordo com as respostas e o
\end{abstract}

\footnotetext{
${ }^{1}$ Doutor em Administração de Empresas pela EAESP-FGV, Professor na Universidade Federal do Paraná. E-mail: jmcrubellate@terra.com.br

${ }^{2}$ Doutor em Sociologia Política pela Universidade Federal de Santa Catarina, Professor na Universidade Estadual de Ponta Grossa e no Programa de Mestrado-Doutorado da Universidade Positivo. E-mail: ariston_azevedo@uol.com. br

${ }^{3}$ Graduado em Administração pela Universidade Estadual de Maringá (UEM). E-mail: r_juniormxpb@hotmail.com
} 
significado atribuído aos critérios oficiais de qualidade. Os resultados sugeriram respostas de aceitação (aquiescência e evasão) e de rejeição dos critérios, que naquelas IES tinham, à época do estudo, significados diversos, uma vez que, para algumas, eles eram fonte de legitimidade, para outras, eram fonte de eficiência no ensino e, para as IES com respostas de rejeição, implicavam em coerção por parte do Governo Federal sobre as Organizações de Ensino Superior. Implicações desses resultados são discutidas nas conclusões.

Palavras-chave: Estratégia; Educação Superior; Qualidade; Ambiente Institucional.

\begin{abstract}
Our main purpose in this paper was to investigate the meaning of education quality in higher education organizations (IES) located in Paraná State, Brazil. To achieve that purpose we planed a survey to describe strategic responses in IES to governmental quality patterns in the period of 2001-2003. We used Brazilian legislation related to Higher Education and a structured questionnaire as main sources of data. The questionnaire was sent to 130 profit Higher Education Organizations during 2004, with 35 valid and complete questionnaires were sent back. We used multivariate methods to analyze answers according to our purposes. Results suggested that education quality was understood in those organizations as a source of institutional legitimacy (in some organizations) and as a source of real improvement of education process, in other organizations. Concluding, we could suggest the importance of further investigation about possible relations between cognitive and interpretive patterns in organizations and strategic responses to environment pressures as a way to understand ways of institutionalizing social processes and structures.
\end{abstract}

Keywords: Strategy; Quality; Institutional Environment.

\title{
1 Introdução
}

Prevalece ainda em nosso meio acadêmico a premissa de que o comportamento individual ou coletivo é de tal forma determinado por amplas estruturas sociais que basta analisar e criticar aquelas estruturas - culturais, políticas, econômicas e legais - para que se compreenda o panorama institucional e se possa antever suas consequências. À luz de desenvolvimentos recentes na Teoria das Organizações e em áreas da Sociologia isso se constitui um engano e fonte de várias limitações. Seguindo orientação da teoria institucional em organizações (SCOTT, 2001; MCKAY, 2001; MACHADO-DA-SILVA; FONSECA e CRUBELLATE, 2005; WEBER e GLYNN, 2006), admite-se que, complementarmente à força das estruturas sociais, há que se analisar o processo pelo qual atores sociais as interpretam quando se quer entender as ações delas decorrentes. Assim, o processo de institucionalização é entendido, neste artigo, como resultado da relação recursiva entre estruturas sociais e a capacidade de agência de atores sociais (GIDDENS, 1984; SEWELL JR., 1992; BARLEY e TOLBERT, 1997; MACHADO-DASILVA, FONSECA e CRUBELLATE, 2005).

Dessa perspectiva, o objetivo central deste estudo foi investigar o significado de qualidade de ensino superior a partir das respostas estratégicas de Organizações de Ensino Superior (IES) do Estado do Paraná aos critérios estabelecidos pelo MEC no período de 2001 a 2003. A problemática explorada neste estudo se circunscreve pela evolução do sistema de ensino superior no Brasil, na última década e meia, como consequência de esforço do Estado brasileiro por ampliar o acesso ao ensino e por definir meios e critérios para avaliação da qualidade de funcionamento daquele sistema, das organizações que o compõem e dos alunos que, de algum modo, são o resultado de todo esse esforço. 
Não estranhamente, contudo, esse amplo esforço parece ter sido conduzido sob o pressuposto de que a via coercitiva era suficiente para provocar alterações no quadro de coisas predominantes no ensino superior brasileiro. De fato, a reestruturação do quadro legal, principalmente após 1995 e 1996, provocou mudanças em vários aspectos do sistema de ensino superior do país. Em especial, parecem merecer destaque a intensificação da expansão do ensino superior privado no país, fenômeno já identificado desde a década de 1970, a utilização, pela primeira vez de forma efetiva, de procedimentos sistematizados de mensuração da qualidade do ensino superior em nível de graduação e a aceitação, pelo menos parcial, de critérios mais objetivos de avaliação, pelo menos até 2003 (ver os textos reunidos em SGUISSARDI, 2000). Apesar disso, muitas foram as críticas elaboradas ao sistema vigente no período de 1995 a 2003 (do qual vários aspectos ainda permanecem no atual sistema de avaliação do ensino superior, vigente desde 2004), tanto por parte da comunidade acadêmica - em especial por pesquisadores da Educação - quanto por parte de gestores de IES. Dentre essas críticas, o quantitativismo do modelo, sua generalização para regiões do país e organizações de ensino extremamente diferentes, e mesmo as inúmeras contradições legais oriundas da sobreposição de decretos e resoluções dos órgãos oficiais, foram algumas das principais.

Uma questão que parece inegável é que, também no Brasil à semelhança do que ocorre em outros países, o ensino superior passa no momento (ou já há pelo menos uma década e meia) por fortes transformações, oriundas da crescente percepção de sua relevância para as políticas de desenvolvimento baseadas na qualificação da mão-de-obra (ver, por exemplo, as discussões em MEYER e ROWAN, 2006a, e também em WOLF, 2002). Por vezes, a preocupação do Estado parece estar meramente na melhoria de índices de acesso escolar, diminuição de evasão, presença de minorias em cursos superiores e outras, resultando em ações que mais se assemelham a comportamento cerimonial em resposta a pressões de organismos internacionais, no sentido já classicamente descrito na nova teoria institucional em organizações (MEYER e ROWAN, 1991).

Mas o que parece evidente é que mudanças importantes estão ocorrendo, ao lado da aquiescência à 'tirania dos números' (nos termos de WOLF, 2002). Estudar tais mudanças ou pelo menos aspectos delas, vinculados às organizações de ensino superior - o locus especial onde todo esse esforço político encontra (ou perde) sua efetivação, é a intenção deste artigo, obviamente dentro de contexto organizacional-regional bastante delimitado. Apesar desse limite, este artigo vem se somar a outros já produzidos no Brasil relativos à mesma questão, isto é, o processo de internalização dos critérios de qualidade por parte de IES e sua análise a partir do escopo teórico da análise institucional. Essa soma de esforços analíticos pode ajudar na compreensão do quadro geral dos resultados das políticas públicas brasileiras para o ensino superior e suas possibilidades e limitações.

\section{Análise institucional de respostas estratégicas}

A tentativa de convergência entre explicações institucionalistas e estratégicas é uma das atuais tendências na teoria organizacional (OLIVER, 1991; ROBERTS e GREENWOOD, 1997; MACHADO-DA-SILVA e FONSECA, 1999; MACHADO-DA-SILVA e SEIFERT JR., 2004). A relevância deste esforço decorre do fato de que, há muito, a teoria institucional vem sendo descrita como teoria de natureza determinista quanto à relação entre ambiente e organizações, enquanto os estudos de estratégia, na sua vertente mais tradicional, estão predominantemente baseados na noção de agentes racionais, autointeressados e plenamente livres para decidir, a despeito de quaisquer tipos de influências contextuais. 
Dentre as tentativas de convergência, destaca-se o estudo de Oliver (1991) que, conjugando pressupostos das teorias institucional e da dependência de recursos, propõe cinco tipos possíveis de respostas estratégicas em reação a características do ambiente institucional. Tais respostas, variando em um contínuo de conformidade em um extremo, e nãoconformidade em outro extremo, são descritas como sendo de aquiescência, compromisso, evasão, desafio ou manipulação e se relacionam, segundo aquela autora, principalmente com características concretas do ambiente institucional. Esses fatores preditores da resposta estratégica predominante são: as causas da resposta (busca por legitimidade ou por eficiência), os constituintes ambientais (multiplicidade de agentes e dependência da organização para com eles), o conteúdo da exigência ambiental (se consistente ou não com os objetivos organizacionais), a forma de controle implícita no padrão institucional (se por meio de coerção ou por meio de difusão cultural) e o contexto ambiental decorrente do padrão (grau de incerteza e de interconectividade provenientes). O modelo analítico de Oliver (1991), baseado principalmente na caracterização do ambiente institucional a partir de seus elementos objetivos e externos, rompeu com o pressuposto de que padrões institucionais constituem-se em forças determinantes das características organizacionais. Por outro lado, ele reafirmou a versão oposta ao determinismo ao admitir que as respostas aos padrões institucionais se deem mediante leitura intencional e interessada dos atores sociais e organizações. Com isso, manteve intacta a dicotomia explicativa do impacto dos padrões institucionais, o que também se evidencia em grande parte da literatura organizacional posterior relativa ao tema (ALDRICH e FIOL, 1994; ROBERTS e GREENWOOD, 1997; DIRSMITH, FOGARTY e GUPTA, 2000).

Mais recentemente, essa dicotomia vem sendo denunciada e abandonada na literatura vinculada à perspectiva institucional de análise organizacional, seguindo pressupostos baseados (principalmente, mas não exclusivamente) na sociologia da estruturação proposta por Giddens (1984), há muito vêm apontando a necessidade de entender-se a relação entre padrões institucionais e capacidade de agência como sendo recursiva, e não dicotômica, na explicação das ações sociais (SCOTT, 2001; ZILBER, 2002; MACHADO-DA-SILVA, FONSECA e CRUBELLATE, 2005). Nessa perspectiva recursiva, as ações estratégicas não são resultantes apenas de contradições e incertezas institucionais (GOODRICK e SALANCIK, 1996) ou de diferentes campos institucionais em competição (BORUM e WESTENHOLZ, 1995), mas surgem em decorrência dos próprios padrões institucionais. Tem-se, então, um fluxo mútuo e simultâneo entre padrões institucionais e reações estratégicas. Tais reações, ao mesmo tempo em que refletem, são ordenadas e possibilitadas por aqueles padrões institucionais, também os reproduzem e re-criam (GIDDENS, 1984; MACHADO-DA-SILVA, FONSECA e CRUBELLATE, 2005).

No sentido recursivo, a relação entre padrões institucionais e agência estratégica, ao invés de dicotômica, pode ser descrita como codependente. Lant e Baum (1995), por exemplo, descrevem a configuração de um campo competitivo como produto de uma lógica recursiva baseada em processo de institucionalização de elementos cultural-cognitivos. Para eles, atores sociais nas organizações (principalmente estrategistas) definem atributos e ações que consideram caracterizadores de determinados grupos competitivos e também adotam esses atributos e ações quando definem as suas próprias organizações como parte daqueles mesmos grupos. Desse modo, tais atores reforçam a noção por eles mesmos construída, ao se adaptarem a padrões de ação que eles próprios ajudaram a construir e disseminar.

Retomando uma das categorizações propostas na teoria institucional em organizações, sintetizada por Scott (2001), isto é, de que instituições se referem a elementos cultural-cognitivos, mas também normativos e legal-regulativos, parece possível adaptar o argumento construtivista 
central de Lant e Baum (1995). Pode-se admitir que agentes organizacionais, principalmente no âmbito estratégico das organizações e em face de convenção normativa socialmente relevante, definem para si o modo como se deveria responder a tal padrão e, então, agem em consonância a isso. Ou, em face de uma lei ou qualquer padrão regulativo, definem para si o que a lei (ou padrão) está prescrevendo e, então, agem em consonância com a prescrição interpretada.

Em todos os casos, a ideia básica é que não se está respondendo a um padrão externo, mas sim ao resultado de um processo de interpretação e também que a própria resposta constitui o mecanismo principal pelo qual aquela interpretação específica adquire conotação de externalidade e passa a constituir o próprio ambiente construído ou ordenado (WEICK, 1969; WEBER e GLYNN, 2006). Assim, esta perspectiva nega o impacto direto do ambiente organizacional sobre as organizações, admitindo que tal impacto é intermediado por processos de interpretação - os esquemas interpretativos dos atores sociais relevantes nas organizações (BARTUNEK, 1984; MACHADO-DA-SILVA, FONSECA e FERNANDES, 1999; ver também WEBER e GLYNN, 2006), podendo-se explicar o tipo de resposta estratégica apenas quando se agrega aquela variável interveniente. O foco em esquemas interpretativos, definidos como crenças ou 'estoques de conhecimentos' que são explicitados de forma intermitente como valores e interesses (RANSON, HININGS e GREENWOOD, 1980), sugere a pertinência de se admitir que o ambiente organizacional e institucional que de fato é relevante para explicar o comportamento estratégico das organizações não é o ambiente objetivo, mas sim o conjunto de características selecionadas e também configuradas pelos próprios atores organizacionais ou o chamado ambiente institucional de referência (WEBER e GLYNN, 2006).

Essa redefinição explicativa parece se desenvolver dentro de um quadro mais amplo de atualização da própria nova teoria institucional em organizações. Segundo Meyer e Rowan (2006b), após um início com foco no entendimento dos processos de isomorfismo organizacional, a nova teoria institucional voltou-se, mais recentemente, à tentativa de explicar a mudança institucional e organizacional, a partir de dois focos analíticos (não excludentes): a inclusão das dimensões de capacidade de agência, poder e interesses de atores sociais iniciadores, participantes ou implicados nos processos de institucionalização social; e a análise de processos de aprendizagem e experimentação social como fonte de mudança.

Ambas as vias põem foco no entendimento da natureza historicamente condicionada dos arranjos institucionais, em complemento à ideia de mudança institucional proveniente apenas de fontes exógenas aos próprios arranjos. Nessa sua nova fase, a nova teoria institucional explica como os arranjos institucionais são provenientes de arranjos previamente existentes, como tais arranjos tanto excluem ações do rol das ações consideradas possíveis, quanto facilita e possibilita novos tipos de ação (MEYER e ROWAN, 2006b).

Com tais pressupostos, a nova teoria institucional em organizações passa a contemplar a possibilidade de entender a dinâmica de elaboração e ação estratégica em organizações como sendo essencialmente influenciada pelos arranjos institucionais quanto, ao mesmo tempo, influenciadora dos próprios arranjos existentes. De fato, estudos anteriores relativos ao sistema brasileiro de ensino superior demonstram que ao responder ao ambiente regulativo, as IES brasileiras parecem atribuir diferentes significados ao mesmo conjunto de exigências legais, fazendo surgir diferentes interpretações e respostas, mesmo quando o comportamento objetivamente observável parece similar (MACHADO-DA-SILVA, 2003; CRUBELLATE e VASCONCELOS, 2007). Esses estudos sugerem fortemente a necessidade de agregar variáveis interpretativas (de natureza local e intersubjetiva, isto é, relativa a grupos de referência - e não meras idiossincrasias) para que se compreenda, dentre outras coisas, a intrincada relação entre aspectos políticos e técnicos, tanto quanto níveis individuais, grupais e macrossociais, 
que parecem marcar as estruturas e ações institucionalizadas, principalmente em organizações. Segundo Rowan (2006), esta é uma necessidade atual da nova teoria institucional, principalmente quando tem por foco a análise de sistemas de ensino, exatamente em função das intensas mudanças pelas quais eles vêm passando nas duas últimas décadas. É nessa perspectiva que se desenvolveu este estudo e é com essa intenção que os dados do estudo são analisados a seguir.

\section{Delineamento da pesquisa e método}

Este estudo pode ser caracterizado como pesquisa de levantamento, apesar de sua intenção apenas exploratória. Para Babbie (1990), os estudos de levantamento (ou surveys) são conduzidos principalmente com o objetivo de fazer inferências a respeito de distribuição de traços e atributos de populações. A estratégia de pesquisa foi descritivo-quantitativa, com utilização de procedimentos multivariados de análise de dados. Para a coleta de dados primários, utilizou-se questionário com 20 questões estruturadas e com respostas do tipo escala de Likert com cinco pontos (de 1, discordo totalmente a 5, concordo totalmente). Esse questionário foi elaborado com base em questionário elaborado por Machado-da-Silva (2003) e Crubellate (2004). O questionário foi adaptado de modo a comportar não apenas questões relativas às respostas estratégicas, mas também questões relativas ao significado atribuído aos critérios de qualidade definidos na legislação brasileira de ensino superior, no período de 2001 a 2003, adaptação que também foi possibilidade, tomando-se como base os resultados obtidos pelos estudos de Machado-da-Silva (2003) e Crubellate (2004).

Foram enviados 130 questionários diretamente aos dirigentes principais de IES localizadas no Estado do Paraná (públicas e privadas, com exceção de universidades públicas e privadas, em função de que se considerou que respostas de um único dirigente seriam pouco representativas, no caso dessas grandes IES). Obteve-se o endereço eletrônico das organizações e de seus dirigentes por meio de relação oficial das IES disponibilizada no mês de junho de 2004, no Website do Instituto Nacional de Estudos e Pesquisas Educacionais Anísio Teixeira (INEP). Os questionários foram enviados por e-mail no mesmo mês de junho de 2004. Obtiveram-se 35 respostas, índice que foi considerado muito bom em relação ao número total de questionários enviados. O critério de seleção dos indivíduos (organizações de ensino superior) foi, portanto, duplo: primeiramente obedeceu ao critério de conveniência (excluindo-se as universidades) e, depois, seguiu-se o critério de adesão voluntária, uma vez que foram analisados os questionários respondidos e encaminhados espontaneamente pelos dirigentes. Os questionários foram submetidos a análise fatorial, inicialmente, e, depois, análise de Cluster, recorrendo-se ao pacote estatístico SPSS. Para a análise de Cluster, utilizou-se o método K-Means, com quatro Clusters, que representam tanto as respostas estratégicas daquelas IES quanto o significado atribuído aos critérios de qualidade, conforme se irá discorrer com detalhes no próximo tópico deste artigo.

Também foram utilizados dados secundários correspondentes à legislação brasileira do ensino superior, além de dados disponibilizados no Website do INEP e relativos aos critérios de qualidade de ensino superior vigentes no país no período de 2001 a 2003. Para tal finalidade, utilizou-se também de dados disponibilizados por outros estudos previamente desenvolvidos no país.. 


\section{Análise dos dados}

As respostas fornecidas pelos dirigentes das 35 IES que participaram do estudo foram submetidas, inicialmente, à análise fatorial, obtendo-se quatro componentes principais explicativos da variação total das respostas. Utilizando-se o método Varimax com Normalização Kaiser para rotação, obteve-se a descrição dos fatores relevantes em cada um dos quatro componentes (Tabela 1).

Em relação ao componente 1, as questões identificadas como mais relevantes foram as de número 2, 7, 8 e 13, que implicavam em aquiescência aos critérios de qualidade oficialmente estabelecidos. Já no componente 2, as questões mais relevantes foram as de número 1, 4, 16 e 18, que se relacionavam à resposta do tipo evasão, principalmente. No componente 3 , as questões mais relevantes foram as de número 11 e 15, e, no componente 4, as questões mais relevantes foram as de número 5 e 20. Estes dois componentes indicavam respostas de rejeição aos critérios, mas por razões diferentes, como se verá posteriormente.

Tabela 1 - Resultado da análise fatorial, com método de extração de análise do componente principal e método de rotação Varimax com normalização Kaiser

\begin{tabular}{|c|c|c|c|c|}
\hline & \multicolumn{4}{|c|}{ COMPONENTE } \\
\hline & 1 & 2 & 3 & 4 \\
\hline Q01 &, 376 & ,728 &, 148 &,- 182 \\
\hline $\mathrm{Q} 02$ & ,699 & $4,767 \mathrm{E}-02$ &,- 287 & $-4,796 \mathrm{E}-02$ \\
\hline$\overline{Q 03}$ & 4,454 &,- 615 &,- 102 &,- 160 \\
\hline$\overline{Q 04}$ & ,380 & ,754 &,- 200 &,- 171 \\
\hline$\overline{Q 05}$ & $2,365 \mathrm{E}-02$ &,- 273 & $-6,013 \mathrm{E}-02$ &, 708 \\
\hline$Q 06$ & ,308 & ,572 &, 168 &,- 317 \\
\hline Q07 &, 675 & ,455 & 258 &, 131 \\
\hline$\overline{Q 08}$ &, 836 & ,135 & $1,552 \mathrm{E}-02$ & $-6,531 \mathrm{E}-02$ \\
\hline Q09 &, 528 & ,491 &,- 102 &,- 196 \\
\hline$Q 10$ & $-4,700 \mathrm{E}-02$ &,- 487 &, 334 & $3,999 \mathrm{E}-02$ \\
\hline$\overline{Q 11}$ &, 117 & $3,784 \mathrm{E}-03$ &, 775 &,- 115 \\
\hline$\overline{Q 12}$ &, 523 & ,288 &,- 414 & $6,729 \mathrm{E}-02$ \\
\hline$\overline{Q 13}$ &, 767 & , 155 &,- 157 &,- 218 \\
\hline$\overline{Q 14}$ &, 563 & $-5,383 \mathrm{E}-02$ &,- 531 &, 147 \\
\hline$\overline{Q 15}$ &,- 250 &,- 331 &, 708 &, 144 \\
\hline$\overline{Q 16}$ &, 119 & ,808 &,- 319 &, 136 \\
\hline$\overline{Q 17}$ & ,537 &, 149 &, 107 & , 128 \\
\hline$\overline{Q 18}$ &, 149 & ,776 &,- 101 &, 101 \\
\hline$Q 19$ & ,409 &, 315 &,- 149 &,- 561 \\
\hline $\bar{Q} 20$ &,- 166 & $6,982 \mathrm{E}-02$ & $5,155 \mathrm{E}-02$ & ,819 \\
\hline
\end{tabular}

Fonte: Dados obtidos pelos autores.

Em seguida, esses componentes foram submetidos à Análise de Cluster. Utilizou-se a técnica K-Means para agrupamento dos dados, definindo-se a priori o total inicial de quatro agrupamentos. Os fatores relevantes identificados na primeira análise indicaram a pertinência de se dividir os respondentes em quatro agrupamentos, em função não apenas das respostas 
estratégicas - três tipos, ou seja, aquiescência, evasão e rejeição, mas também em função do significado atribuído aos critérios. Os resultados obtidos com essa técnica multivariada de análise são descritos na Tabela 2, na qual podem ser observados os componentes relevantes em cada um dos agrupamentos ou clusters.

Tabela 2 - Resultado da Análise de Cluster com método K-Means

\begin{tabular}{c|c|c|c|c}
\hline \multirow{2}{*}{} & \multicolumn{4}{|c}{ CLUSTER } \\
\cline { 2 - 5 } & $\mathbf{1}$ & $\mathbf{2}$ & $\mathbf{3}$ & $\mathbf{4}$ \\
\hline AQUIESCÊNCIA & $-1,00504$ & $-1,13143$ &,- 11865 &, 75019 \\
\hline EVASÃO & $-2,33301$ &, 74322 &, 10367 &, 05397 \\
\hline REJEIÇÃO 1-Instrumental &, 56824 &,- 76672 &, 24769 &, 08956 \\
\hline REJEIÇÃ O 2-Injustiça &, 77159 &, 38928 & $-1,44619$ &, 49850 \\
\hline
\end{tabular}

Fonte: Dados obtidos pelos autores.

\section{Agrupamento 1}

Neste agrupamento, o fator mais relevante observado foi aquele relativo ao componente 4 , designado pelo termo 'rejeição 2 - injustiça'. Como se observou anteriormente, as questões mais pertinentes para designar esse fator foram as questões 5 e 20 do questionário aplicado aos dirigentes, que se referiam a peculiaridades das IES que poderiam impedi-las de atender aos critérios de qualidade ou pelo menos dificultar esse atendimento (questão 5: "os critérios de avaliação estabelecidos pelo MEC são injustos porque desconsideram características e dificuldades específicas de cada instituição de ensino"; e questão 20: "Cada IES possui características e dificuldades específicas, por isso os critérios de avaliação do MEC, ou pelo menos os prazos para seu atendimento, deveriam ser flexibilizados"). Secundariamente, observou-se também a importância de outro componente (componente 3) na caracterização deste primeiro agrupamento. O componente 3 recebe sua definição de duas questões que expressavam discordância quanto à validade do modelo de avaliação então vigente, baseado em critérios objetivos e predominantemente quantitativos de mensuração da qualidade do ensino superior.

Esses elementos indicam que, além da resposta estratégica de rejeição dos critérios, pode-se identificar, nos respondentes do agrupamento 1, uma interpretação dos critérios oficialmente prescritos como não sendo instrumentalmente válidos, ou seja, como não possuindo relação com efetiva qualidade de ensino e, mais ainda, como se constituindo em exercício de coerção por parte do Estado sobre organizações de ensino, uma vez que são impostos de forma homogênea sobre organizações que não são homogêneas em suas características e suas condições. É interessante observar também que são três organizações que compõem este agrupamento, duas das quais localizadas no interior do Estado do Paraná, em cidades de porte médio (entre 100 e 150 mil habitantes). Das três IES, apenas uma era, à época, classificada junto ao MEC como tendo natureza institucional de organização privada em sentido estrito. As outras duas tinham orientação confessional (uma delas) e comunitária (a outra), tendo essas duas IES atuação já bastante tradicional nas suas respectivas cidades de localização, com mais de duas décadas e meia de existência. 


\section{Agrupamento 2}

Neste agrupamento, o fator mais relevante foi aquele relativo ao segundo componente. Observou-se, anteriormente, que aquele componente era derivado das questões 1, 4, 16 e 18, que se refletiam uma forma de pensar que vinculava os critérios oficiais de qualidade com a sobrevivência comercial da IES (principalmente, questão 4: "atender os critérios de avaliação do MEC é importante por permitir a construção de uma imagem positiva para a instituição sob minha direção"; questão 16: "atender os critérios do MEC é importante porque eles são condição necessária para a renovação de seu credenciamento e para a manutenção do reconhecimento dos cursos oferecidos"; questão 18: "eu acredito que uma instituição que atende a todos os critérios do MEC adquire vantagem competitiva em relação a outras instituições que não conseguem atender àqueles critérios"). Em razão disso, parece plausível reconhecer que a resposta estratégica desse segundo agrupamento é predominantemente de evasão (termo que se utilizou para designar o agrupamento).

Deve-se notar que há um sentido específico na ideia de evasão, utilizada para designar esse cluster de respondentes, uma vez que não se refere necessariamente ao comportamento organizacional voltado a evitar diretamente a avaliação por agentes externos. A evasão se refere, no caso dessas IES e de acordo com as respostas fornecidas por seus dirigentes principais, ao fato de que o objetivo principal em se atender aos critérios oficiais (e também em se tentar obter boas notas nas avaliações oficiais) está mais próximo ao interesse por obtenção de legitimidade, de melhoria da imagem junto à comunidade e aos usuários das IES, do que propriamente por se acreditar no valor efetivo dos critérios e avaliações para melhorar a qualidade do ensino superior. As IES deste agrupamento 2 possuem resposta oposta, no seu significado, à resposta das IES do agrupamento 1: apesar de aceitarem os critérios como necessários, tais critérios não são interpretados como fonte de eficiência no ensino, e sim como fonte de legitimidade junto a usuários, junto ao Estado avaliador e também junto ao mercado usuário do serviço. Claramente as razões para atendimento dos critérios de qualidade são cerimoniais, mais do que instrumentais, nestas IES.

Especificamente quanto às IES componentes deste agrupamento, os nove respondentes identificados são todos classificados como sendo Instituições de Ensino privadas em sentido estrito. Dessas, quatro se localizam em grandes centros (capital do Estado e duas outras cidades de grande porte) e cinco delas são bastante novas (fundadas na segunda metade da década de 1990), o que pode explicar a busca por legitimidade.

\section{Agrupamento 3}

Neste agrupamento, o fator mais relevante foi aquele relativo ao terceiro componente, referente às questões 11 e 15, relativas, por sua vez, à suposição de impossibilidade de avaliação da qualidade de ensino superior por meio dos procedimentos então existentes (questão 11: "toda instituição de ensino superior deve ter como objetivo ir além dos critérios exigidos pelo MEC"; questão 15: "não se pode avaliar qualidade educacional com números, sejam números relativos à quantidade de livros, de equipamentos, de salas de aula ou de professores pósgraduados"). Esses dados sugeriram que, neste agrupamento, se encontram IES cuja resposta estratégica é de rejeição dos critérios oficiais de qualidade, por uma razão bastante específica, que é a crença na não efetividade instrumental dos mesmos. Em outras palavras, o significado 
de qualidade de ensino, nestas IES, parece compreender uma realidade mais complexa do que se pode descrever com notações quantitativas, exigindo procedimentos para além daqueles utilizados então pelo Estado brasileiro. Talvez seja interessante observar que, em face da impossibilidade objetiva naquele momento de não se submeter aos procedimentos oficiais de avaliação, uma possível consequência desse tipo de interpretação seja a elaboração de ações de evasão, no sentido tradicionalmente encontrado na literatura relativa à questão (por exemplo, MEYER e ROWAN, 1991; OLIVER, 1991; CRUBELLATE e VASCONCELOS, 2007). Ou seja, a emergência de comportamento de atendimento apenas formal daqueles critérios e procedimentos, sem sua efetivação no contexto objetivo do ensino (a sala de aula).

Fizeram parte desse agrupamento nove IES, das quais apenas duas na capital do Estado (uma em Curitiba e uma na região metropolitana de Curitiba), e o restante em cidades de pequeno ou médio porte, do interior do Estado do Paraná. De todas essas IES, apenas uma delas classificou-se como confessional; as demais eram IES privadas em sentido estrito. O tempo de existência dessas IES foi bastante variado, com predominância de IES mais jovens, mas sem que isso se constituísse em um padrão razoavelmente definido.

\section{Agrupamento 4}

Finalmente, o agrupamento 4 teve no componente 1 o seu fator mais relevante. Esse componente se refere às questões 2, 7, 8 e 13, que se referiam explicitamente à relação cognitiva entre atendimento dos critérios de qualidade oficialmente estabelecidos e melhor formação dos alunos (questão 2: "a exigência de capacitação docente pelo MEC justifica-se porque é garantia de qualidade de ensino para alunos dos cursos de graduação"; questão 7: "acredito que o atendimento de todos os critérios estabelecidos pelo MEC para os cursos superiores seja condição necessária para que os alunos da Instituição sob minha direção obtenham bom resultado no Exame Nacional de Cursos (Provão)"; questão 8: "acredito que o atendimento de todos os critérios estabelecidos pelo MEC para os cursos superiores seja condição necessária para que a Instituição sob minha direção forme bons profissionais"; questão 13: "uma instituição de ensino superior que atenda integralmente os critérios do MEC sempre oferecerá ensino de melhor qualidade que outra instituição que não atende a tais critérios na sua íntegra"). Não gratuitamente, chamou-se tal agrupamento de 'aquiescência', porque essa parece ser a resposta estratégica das IES alocadas neste cluster para as exigências oficiais quanto à qualidade.

Em termos do significado daqueles critérios e procedimentos, esse agrupamento é oposto principalmente às IES do terceiro agrupamento: aqui, acredita-se que há relação direta entre os critérios e a real qualidade de ensino oferecida aos alunos. Nessas IES, portanto, os critérios oficiais significam efetivamente qualidade de ensino; eles têm um valor instrumental naquelas IES ou, pelo menos, é assim que seus dirigentes entendem que a eles devem se referir.

Os respondentes identificados nesse agrupamento foram mais numerosos do que em relação aos outros agrupamentos: 16 IES no total. Dessas, a metade está localizada na Capital e região metropolitana de Curitiba ou em grandes cidades e regiões do interior do Estado (Maringá, principalmente, e também Cascavel e Foz do Iguaçu), o que parece caracterizar esse grupo. Os outros respondentes se localizam em cidades de porte médio do interior. A maioria dessas IES foi iniciada na década de 1990 e, com exceção de uma (pública), as demais são privadas em sentido estrito. 
Com base nesses dados descritivos, elaboram-se, nas considerações finais, implicações do estudo tanto para a noção de qualidade no ensino superior quanto para a teoria institucional, que serviu de referência teórica para o estudo.

\section{Considerações finais}

O crescimento de uma organização ocorre quando ela desenvolve gradualmente suas atOs resultados reportados neste artigo são coerentes com resultados de outros estudos realizados no Brasil, igualmente em sistemas de ensino superior e que também apontaram ser as respostas do tipo 'aquiescência' as numericamente mais predominantes (MACHADO-DASILVA, 2003; CRUBELLATE e VASCONCELOS, 2007). Por outro lado, os mesmos resultados parecem indicar que o sistema de avaliação do ensino superior, nos moldes vigentes até 2003 (considerado neste estudo), não se encontrava ainda institucionalizado em elevado grau, pelo menos no grupo de IES abrangidas neste estudo. Isso se observa mais pelo significado atribuído àquele sistema do que propriamente ao número de casos de rejeição dos critérios, que foi relativamente baixo, como já se notou.

Neste sentido, deve-se notar que, com exceção dos respondentes agrupados no quarto agrupamento ("aquiescência"), os demais (mais da metade) não parecem refletir padrões de interpretação que igualem o atendimento dos critérios de qualidade prescritos oficialmente, à época do estudo, com real qualidade de ensino. Em um dos agrupamentos, o significado atribuído foi o exato inverso disso, aliás. Por outro lado, o notório esforço que a ampla maioria de IES fez, desde a implantação do "Provão" em 1995, para alcançar boas avaliações nos procedimentos de verificação da qualidade ou para que seus alunos obtivessem boas notas nos exames reflete (o que é de conhecimento público e que se refere a todas as regiões do país), à luz dos dados desses estudos, que seus gestores ou dirigentes identificam suas organizações como sendo altamente dependentes do Estado, em primeiro lugar. Tal dependência explicaria porque, mesmo em face da não concordância parcial com o modelo avaliativo, houve tamanho esforço para atendê-lo e tamanho alarde nas circunstâncias em que se obtinha boas notas nas avaliações. Indica também que naquelas organizações se tinha como evidente o fato de que a população em geral havia internalizado aqueles critérios e procedimentos como evidência de qualidade. Daí a preocupação com seu atendimento, por razões de legitimidade (frente ao Estado) e por razões utilitárias (frente ao mercado consumidor de ensino superior).

Isso revela um interessante "jogo" ainda bastante importante no contexto do sistema de ensino superior brasileiro, no que tange à força do Estado enquanto agente controlador, mesmo sob a lógica credencialista que se instalou no período aqui analisado. Aparentemente o que se pode observar é que, naquele período, o controle do Estado passou a se dar de modo mais indireto, via mercado e sociedade civil, não deixando, contudo, de ser tão forte quanto o foi em outros períodos. Sem dúvida mudou a forma de controle sobre as organizações, com consequências importantes. Isso corrobora a noção de que as organizações não respondem ao ambiente institucional - principalmente o ambiente regulatório - isolada ou mesmo diretamente. Elas o fazem em acordo com outras organizações e atores sociais importantes em seu contexto, isto é, na medida da interpretação e das ações (ou ações supostas) de outras organizações e atores.

A principal consequência disso é que o entendimento da ação organizacional passa por entender antes aspectos de identidade, de imersão social e de interpretação quanto ao contexto ambiental no qual a organização atua, desenvolvidos nas próprias organizações. Neste sentido, parece necessário privilegiar-se análises que contemplem tanto níveis macrossociais 
quanto níveis microanalíticos, para que se possa entender a relação entre organizações e seus ambientes institucionais, principalmente regulativos.

Ainda é importante destacar que os resultados deste estudo reforçam resultados encontrados previamente, relativos também ao sistema de ensino superior brasileiro, na sua interface com a política oficial de avaliação da qualidade. Aqui, como em outros estudos, respostas de aceitação dos critérios e procedimentos oficiais de mensuração da qualidade estiveram vinculados, pelo menos em algumas IES, com a busca por legitimidade, mas também por interesses técnicos de efetiva melhoria da qualidade. Nesse sentido, é interessante observar que os dados permitem conhecer aspectos relativos à internalização de preocupações técnicas em um contexto que, até há algumas décadas, era predominantemente marcado (no Brasil como em outros países - ver, por exemplo, os textos de WEICK, 1976 e MEYER e ROWAN, 1978) por relações frouxas entre intervenções ou exigências externas, ou mesmo administrativas, e os processos efetivados no contexto operativo cotidiano, no caso, as salas de aula ou a docência e pesquisa, em termos mais gerais. Há que se notar que, neste sentido, o modelo avaliativo implementado no período aqui sob investigação parece ter conseguido, mesmo que toscamente, interferir na dinâmica operativa do ensino superior, ao menos em algumas das organizações aqui investigadas (que, é bom que se relembre, eram predominantemente privadas).

Nesse mesmo sentido, o modelo avaliativo parece ter trazido à dinâmica institucional do sistema de ensino superior brasileiro, de forma mais ampla que em qualquer outro momento anterior, a pressão do mercado de usuários, atuais ou potenciais, de educação superior. As consequências benéficas e principalmente perniciosas dessa 'virada para o mercado' no setor merecem ser exploradas com maior detalhe, mas isso vai além do que permitem os dados obtidos neste estudo. Ele serve, pelo menos, para indicar que essa parece ser uma nova - e forte - presença no sistema de ensino superior brasileiro (note-se, por exemplo, o significado dos critérios como fonte de legitimidade frente ao mercado, neste estudo, como em outros, como o de CRUBELLATE e VASCONCELOS, 2007). Os estudos até aqui desenvolvidos sobre respostas estratégicas em organizações brasileiras de ensino superior permitem, pelo menos, vislumbrar o modo como o 'mercado', enquanto origem de pressões a serem atendidas, vem sendo internalizado nas ações das IES. Isso vem ocorrendo de modo indireto, via a suposta expectativa quanto à eficiência técnica (isto é, qualidade de ensino nos moldes quantitativos propostos pelo Estado) que as IES devem demonstrar. Não atender a tais expectativas, acredita significativa parte dos gestores de IES no Brasil, implica em menor atração de novos alunos, perda de espaço frente à "concorrência" e, consequentemente, perda de recursos financeiros e lucro.

Finalmente, esses aspectos, apesar de novos, tanto no contexto da nova teoria institucional em organizações quanto no contexto empírico do sistema de ensino superior brasileiro, parecem não ter sido revertidos (talvez apenas amortecidos temporariamente) pela mudança promovida na esfera federal do Governo, sob a orientação do Partido Trabalhista, no Brasil, a partir de 2004. A importância dessas questões parece inegável em face mesmo das contínuas reformulações e planos que continuam a surgir no cenário político e legal brasileiro (como o novo Plano de Desenvolvimento da Educação (PED), apresentado à sociedade brasileira em abril de 2007) e que indicam que o debate quanto a qualidade, avaliação e controle do ensino superior pode estar passando por uma fase de arrefecimento temporário ou até de "trégua", mas não foi nem de longe resolvido. 


\section{Referências}

ALDRICH, H.; FIOL, C. M. Fools rush in? The institutional context of industry creation. Academy of Management Review, v. 19, n. 4, p. 645-670, 1994.

BABBIE, E. Survey research methods. 2nd ed. New York: Wadsworth Publishing, 1990.

BARLEY, S.; TOLBERT, P. Institutionalization and structuration: studying the links between action and institution. Organization Studies, v. 18, n. 1, p. 93-117, 1997.

BARTUNEK, J. Changing interpretive schemes and organizational restructuring: the example of a religious order. Administrative Science Quarterly, v. 29, p. 355-372, 1984.

BORUM, F.; WESTENHOLZ, A. The incorporation of multiple institutional models: organizational field multiplicity and the role of actors. In: SCOTT, W.R.; CHRISTENSEN, S. (Eds.). The institutional construction of organizations. Thousand Oaks: Sage, 1995. p.113-134.

CRUBELLATE, J. Parâmetros de qualidade de ensino superior: análise institucional em IES privadas do Estado de São Paulo. 2004. 358 f. Tese (Doutorado em Administração de Empresas) - Escola de Administração de Empresas da Fundação Getúlio Vargas de São Paulo, São Paulo, 2004.

CRUBELLATE, J.; VASCONCELOS, F. Respostas estratégicas ao ambiente legal: estudo da institucionalização da qualidade de ensino em IES privadas do estado de São Paulo. In: ENCONTRO DE ESTUDOS EM ESTRATÉGIA, 3., 2007, São Paulo. Anais... Rio de Janeiro: ANPAD, 2007. 1 CD.

DIRSMITH, M.; FOGARTY, T.; GUPTA, P. Institutional pressures and symbolic displays in a GAO context. Organization Studies, v. 21, n. 3, p. 515-537, 2000.
GIDDENS, A. The constitution of society. Berkeley: University of California Press, 1984.

GOODRICK, E.; SALANCIK, G. Organizational discretion in responding to institutional practices:hospitals and cesarean births.

Administrative Science Quarterly, v.41, p.1-28, 1996.

LANT, T.; BAUM, J. Cognitive sources of socially constructed competitive groups: examples from the Manhattan Hotel Industry. In: SCOTT, W. R.; CHRISTENSEN, S. (Eds.). The institutional construction of organizations. Thousand Oaks: Sage, 1995. p. 15-38.

MACHADO-DA-SILVA, C. Respostas estratégicas da Administração e Contabilidade ao sistema de avaliação da CAPES. Organizações \& Sociedade, v. 10, n. 28, p. 63-77, 2003.

MACHADO-DA-SILVA, C.; SEIFERT JR., R. Ambiente, recursos e interpretação organizacional: um modelo para análise de estratégias de internacionalização. In: ENANPAD, 2004, Curitiba. Anais ... Rio de Janeiro: ANPAD, 2004. 1 CD.

MACHADO-DA-SILVA, C.; FONSECA, V.; CRUBELLATE, J. M. Estrutura, agência e interpretação: elementos para uma abordagem recursiva do processo de institucionalização.

Revista de Administração Contemporânea, v. 9, 1. ed. esp., p. 9-40, 2005.

MACHADO-DA-SILVA, C.; FONSECA, V. Competitividade organizacional: conciliando padrões concorrenciais e padrões institucionais. In: VIEIRA, M.; OLIVEIRA, L. (Orgs.).

Administração contemporânea: perspectivas estratégicas. São Paulo: Atlas, 1999. p. 27-39.

MACHADO-DA-SILVA, C.; FONSECA, V.; FERNANDES, B. Mudança e estratégia nas organizações: perspectivas cognitiva e institucional. In: VIEIRA, M.; OLIVEIRA, L. 
(Orgs.). Administração contemporânea: perspectivas estratégicas. São Paulo: Atlas, 1999. p.102-118.

MCKAY, R. Organizational responses to an environmental bill of rights. Organization Studies, v. 22, n. 4, p. 625-568, 2001.

MEYER, J.; ROWAN, B. The structure of educational organizations. In: MEYER, M. (Ed.).

Environments and organizations. San Francisco: Jossey Bass, 1978. p. 78-109.

MEYER, J.; ROWAN, B. Institutionalized organizations: formal structure as myth and ceremony. In: POWELL, W.; DIMAGGIO, P. The new institutionalism in organizational analysis. Chicago: The University of Chicago Press, 1991. p. 41-62.

MEYER, H.-D.; ROWAN, B. (Eds.). The new institutionalism in education. Albany: State University of New York Press, (2006a).

MEYER, H.-D.; ROWAN, B. Institutional analysis and the study of education. In: MEYER, H.-D.; ROWAN, B. (Eds.). The new institutionalism in education. Albany: State University of New York Press, 2006b. p. 1-14.

OLIVER, C. Strategic responses to institutional processes. Academy of Management Review, v. 16, n. 1, p. 145-179, 1991.

RANSON, S.; HININGS, B.; GREENWOOD, $R$. The structuring of organizational structures. Administrative Science Quarterly, v. 25, p. 1-17, 1980.

ROBERTS, P.; GREENWOOD, R. Integrating transaction cost and institutional theories: toward a constrained-efficiency framework for understanding organizational design adoption.

Academy of Management Review, v. 22, n. 2, p. 346-373, 1997.

ROWAN, B. The new institutionalism and the study of educational organizations: changing ideas for changing times. In: MEYER, H.-D.; ROWAN, B. (Eds.). The new institutionalism in education. Albany: State University of New York Press, 2006. p. 15-32.
SCOTT, W. R. (2001). Institutions and organizations. 2 nd. Thousand Oaks: Sage.

SEWELL JR., W. H. A theory of structure: duality, agency, and transformation. The American Journal of Sociology, v. 98, n.1, p. 01-29, 1992.

SGUISSARDI, V. (Org.). Educação superior: velhos e novos desafios. São Paulo: Xamã, 2000.

WEBER, K.; GLYNN, M. A. Making sense with institutions: context, thought and action in Karl Weick's theory. Organization Studies, v. 27, n. 11, p. 1639-1660, 2006.

WEICK, K. The psychology of organizing. Reading: Addison-Wesley, 1969.

WEICK, K. Educational organizations as loosely coupled systems. Administrative Science Quarterly, v. 21, p. 1-19, 1976.

WOLF, A. Does education matter? Myths about education and economic growth. London: Penguin Books, 2002.

ZILBER, T. Institutionalization as an interplay between actions, meanings, and actors: the case of a rape crisis center in Israel. Academy of Management Journal, v. 45, n. 1, p. 234-254, 2002. 